\title{
Initiating guideline-concordant gout treatment improves arterial endothelial function and reduces intercritical inflammation: a prospective observational study
}

Michael Toprover ${ }^{1,2 \dagger}$, Binita Shah ${ }^{3,4 \dagger}$, Cheongeun Oh ${ }^{5}$, Talia F. Igel ${ }^{1,2}$, Aaron Garza Romero ${ }^{1,2}$, Virginia C. Pike ${ }^{1,2}$, Fatmira Curovic $^{3,4}$, Daisy Bang ${ }^{1,2}$, Deana Lazaro', Svetlana Krasnokutsky ${ }^{1,2}$, Stuart D. Katz ${ }^{4+}$

and Michael H. Pillinger ${ }^{1,2^{*}+}$ (D)

\begin{abstract}
Background: Patients with gout have arterial dysfunction and systemic inflammation, even during intercritical episodes, which may be markers of future adverse cardiovascular outcomes. We conducted a prospective observational study to assess whether initiating guideline-concordant gout therapy with colchicine and a uratelowering xanthine oxidase inhibitor $(\mathrm{XOI})$ improves arterial function and reduces inflammation.

Methods: Thirty-eight untreated gout patients meeting American College of Rheumatology (ACR)/European League Against Rheumatism classification criteria for gout and ACR guidelines for initiating urate-lowering therapy (ULT) received colchicine ( $0.6 \mathrm{mg}$ twice daily, or once daily for tolerance) and an XOI (allopurinol or febuxostat) titrated to ACR guideline-defined serum urate $(\mathrm{s} U)$ target. Treatment was begun during intercritical periods. The initiation of colchicine and $\mathrm{XOI}$ was staggered to permit assessment of a potential independent effect of colchicine. Brachial artery flow-mediated dilation (FMD) and nitrate-mediated dilation (NMD) assessed endothelium-dependent and endothelium-independent (smooth muscle) arterial responsiveness, respectively. High-sensitivity C-reactive protein (hsCRP), IL-1 $\beta$, IL-6, myeloperoxidase (MPO) concentrations, and erythrocyte sedimentation rate (ESR) assessed systemic inflammation.

(Continued on next page)
\end{abstract}

\footnotetext{
* Correspondence: michael.toprover@nyulangone.org

${ }^{+}$Michael Toprover and Binita Shah are co-first authors.

†Stuart D. Katz and Michael H. Pillinger are co-senior authors.

'Section of Rheumatology, VA New York Harbor Health Care System, New

York, NY, USA

${ }^{2}$ Division of Rheumatology, NYU Grossman School of Medicine, NYU Hospital for Joint Diseases Suite 1410, 301 East 17th Street, New York, NY 10003, USA

Full list of author information is available at the end of the article
}

(c) The Author(s). 2020 Open Access This article is licensed under a Creative Commons Attribution 4.0 International License, which permits use, sharing, adaptation, distribution and reproduction in any medium or format, as long as you give appropriate credit to the original author(s) and the source, provide a link to the Creative Commons licence, and indicate if changes were made. The images or other third party material in this article are included in the article's Creative Commons licence, unless indicated otherwise in a credit line to the material. If material is not included in the article's Creative Commons licence and your intended use is not permitted by statutory regulation or exceeds the permitted use, you will need to obtain permission directly from the copyright holder. To view a copy of this licence, visit http://creativecommons.org/licenses/by/4.0/ The Creative Commons Public Domain Dedication waiver (http://creativecommons.org/publicdomain/zero/1.0/) applies to the data made available in this article, unless otherwise stated in a credit line to the data. 


\begin{abstract}
(Continued from previous page)
Results: Four weeks after achieving target $\mathrm{s} U$ concentration on colchicine plus an $\mathrm{XOI}, \mathrm{FMD}$ was significantly improved (58\% increase, $p=0.03)$. hSCRP, ESR, IL-1 $\beta$, and IL-6 also all significantly improved (30\%, 27\%, 19.5\%, and $18.8 \%$ decrease respectively; all $p \leq 0.03$ ). Prior to addition of $\mathrm{XOI}$, treatment with colchicine alone resulted in smaller numerical improvements in FMD, hsCRP, and ESR (20.7\%, 8.9\%, 13\% reductions, respectively; all nonsignificant), but not IL-1 $\beta$ or IL-6. MPO and NMD did not change with therapy. We observed a moderate inverse correlation between hsCRP concentration and FMD responsiveness $(R=-0.41, p=0.01)$. Subgroup analyses demonstrated improvement in FMD after achieving target $\mathrm{SU}$ concentration in patients without but not with established cardiovascular risk factors and comorbidities, particularly hypertension and hyperlipidemia.
\end{abstract}

Conclusions: Initiating guideline-concordant gout treatment reduces intercritical systemic inflammation and improves endothelial-dependent arterial function, particularly in patients without established cardiovascular comorbidities.

Keywords: Gout, Hyperuricemia, Subclinical cardiovascular disease, Inflammation, Urate-lowering therapy, Colchicine, Xanthine oxidase inhibitor, Allopurinol, Flow-mediated dilation, C-reactive protein

\section{Background}

Gout is the most common crystal arthropathy and the leading cause of inflammatory arthritis [1]. The past several decades have seen a surge in gout prevalence, along with associated increases in functional impairment and diminished health-related quality of life [2]. Epidemiological evidence suggests an association between gout and cardiovascular disease $[3,4]$. In addition to increased rates of traditional cardiovascular risk factors in patients with gout $[5,6]$, gout conveys an independent risk for adverse cardiovascular outcomes [7, 8]. The fundamental pathological processes associated with gout, hyperuricemia, and local and systemic inflammation are independently implicated in the development and progression of cardiovascular disease [9-11] and may contribute to the increased cardiovascular risk observed in gout patients.

Management guidelines from the American College of Rheumatology (ACR) and the European League Against Rheumatism (EULAR) emphasize that most gout patients should be treated with a urate-lowering therapy (ULT), ideally a xanthine oxidase inhibitor (XOI), to a serum urate $(\mathrm{sU})$ of $\leq 6.0 \mathrm{mg} / \mathrm{dL}$, or potentially $\leq 5.0 \mathrm{mg} /$ $\mathrm{dL}$ in the case of patients with tophaceous gout [12-14]. Because urate lowering transiently raises the risk of gout flares, gout treatment guidelines additionally recommend daily administration of an anti-inflammatory agent such as colchicine in the first months of ULT [13-15]. Whether management of gout per current guidelines reduces the risk of adverse cardiovascular outcomes is an area of ongoing investigation. Several studies suggest that colchicine use may be associated with a reduction in cardiac events both in gout patients $[16,17]$ and in non-gout patients at high cardiovascular risk $[18,19]$. However, these studies were either retrospective or open-label or, in the case of the randomized Colchicine Cardiovascular Outcomes (COLCOT) trial, showed benefit largely through reductions in the cardiovascular endpoint of urgent revascularization [18]. Other studies suggest that XOIs may reduce mortality and cardiac events among individuals with hyperuricemia or gout [20-23], but this has not been evaluated in a large randomized trial. Therefore, delineating the underlying mechanism(s) of potential gout treatment benefit remains of pressing importance.

The Canakinumab Anti-Inflammatory Thrombosis Outcomes Study (CANTOS) demonstrated that reducing inflammation can reduce risk of cardiovascular disease [24], and it is possible that colchicine may reduce cardiovascular risk via a reduction in chronic inflammation. Alternatively, we recently reported that, compared to non-gout healthy controls, patients with gout have impairment of both brachial artery flow-mediated dilation (FMD) and nitrate-mediated dilation (NMD), measurements of endothelium-dependent and endotheliumindependent (smooth muscle) arterial responsiveness respectively [25]. Impaired endothelial function assessed by FMD correlates with risk for future coronary events [26-29], and studies both in vitro and in animal models indicate that urate may impede the ability of endothelial cells to generate nitric oxide and thus limit arterial responsiveness [30,31]. Therefore, both endothelial function and inflammation may be targets for lowering cardiovascular risk in patients with gout. The objective of this observational study was to determine the effects of initiating guideline-concordant gout treatment with colchicine plus an XOI (colchicine+XOI) on arterial endothelial function and systemic inflammation in patients with intercritical gout.

\section{Methods}

Study design and setting

This prospective observational study evaluated patients with intercritical gout who were being initiated on ACR 
guideline treatment to achieve target $\mathrm{sU}$ concentration by their physicians (rheumatologists or primary care physicians) in the ambulatory care offices of our three hospitals (NYU Langone Medical Center, Bellevue Hospital Center, and the VA New York Harbor Hospital). The study was approved by the institutional review boards of all three institutions, and all subjects provided informed consent.

\section{Participating subjects}

Patients were eligible if they were at least 18 years of age and met ACR/EULAR classification criteria for gout [32], as well as ACR guidelines for initiating ULT [12], but were not currently receiving gout treatment. Patients were excluded if they had received colchicine or any specific ULT (allopurinol, febuxostat, probenecid, or pegloticase) within the past 30 days, or had prior intolerance or contraindication to treatment with colchicine, or with both allopurinol and febuxostat. Patients were further excluded if they were actively taking glucocorticoids or non-steroidal anti-inflammatory drugs on a chronic basis for any reason or had chronic kidney disease $\geq$ stage 4 .

\section{Treatment protocol}

Initiation of gout therapy was at the discretion of the subject's physician, as was the choice and management of ULT. However, all subjects' physicians agreed to follow a general plan provided by the investigators. Subjects slated for initiation of treatment underwent a baseline assessment of demographics, co-morbidities, and laboratory data including $\mathrm{sU}$ concentration, brachial artery function (FMD and NMD), and inflammatory markers (visit one). Treatment was initiated with colchicine $0.6 \mathrm{mg}$ twice daily, with adjustment to once daily for intolerance or renal function (discretion of the treating physician). After 6 weeks of colchicine-only treatment, subjects underwent reassessment of sU concentration, brachial artery function, and inflammatory markers (visit two). While continuing colchicine, subjects were then started on XOI therapy (allopurinol 100 $\mathrm{mg}$ or febuxostat $40 \mathrm{mg}$ daily at the discretion of the treating physician). sU was assessed every 3 to 5 weeks, and XOI was titrated to achieve a target sU concentration of $\leq 6.0 \mathrm{mg} / \mathrm{dL}$ ( $\leq 5.0 \mathrm{mg} / \mathrm{dL}$ in subjects with tophi). Once target $\mathrm{sU}$ concentration was achieved, subjects were maintained on stable doses of colchicine and XOI for four additional weeks, followed by reassessment of sU concentration, brachial artery function, and inflammatory markers (visit three). If any patient experienced a gout flare during a scheduled treatment assessment, the assessment was delayed until 1 week after resolution of the flare. The treatment approach was consistent with ACR 2012 Treatment Guidelines, which recommend the initiation of a prophylactic anti-inflammatory drug prior to or concurrently with an XOI, followed by titration of the XOI to target sU concentration $[12,15]$.

\section{Arterial function}

Assessment of arterial function by FMD and NMD has been previously described [25, 33, 34]. Briefly, FMD was measured using a high-resolution duplex ultrasound imaging system (SonoSite, Inc., Bothell, WA, USA) connected to an $11-\mathrm{MHz}$ linear array transducer with an axial resolution of $<0.1 \mathrm{~mm}$ and a computerassisted edge detection system (AMS software). Brachial artery diameter (trailing edge of anterior intima-lumen interface to leading edge of posterior lumen-intima interface) was measured at end-diastole before and after transient arterial occlusion (forearm blood pressure cuff inflation to $50 \mathrm{mmHg}$ above systolic blood pressure for 5 min) [35]. FMD was determined as percent change in brachial diameter from baseline to $1 \mathrm{~min}$ after occlusion release (mean of 3 separate measurements). Immediately after, NMD was determined as percent change in brachial artery diameter from baseline (pre-blood pressure cuff inflation) to $5 \mathrm{~min}$ after sublingual administration of nitroglycerin $(0.4 \mathrm{mg})$. Whenever possible, assessments were performed in the morning in a fasting state, and subjects delayed any usual beta and/or calcium channel blocker doses until after the procedure. Subjects were permitted to opt out of NMD testing without being removed from the study and were excluded from NMD testing if their primary care physician or cardiologist recommended against it for any reason. In our laboratory, brachial artery reactivity in healthy adult subjects is $5.89 \% \pm 2.88 \%$ (95\% confidence interval $=4.53-7.23 \%$ ), and brachial artery dilation response to nitroglycerin in adults without known heart disease is $24.7 \pm 6.9 \%$ (95\% confidence intervals $11.8 \%$, $34.5 \%)[34,36]$.

\section{Inflammatory markers}

$\mathrm{sU}$, high-sensitivity C-reactive protein (hsCRP), and erythrocyte sedimentation rate (ESR) were measured in standard clinical laboratories. For the measurement of IL-1 $\beta$, IL-6, and myeloperoxidase (MPO), heparinanticoagulated blood was centrifuged within $30 \mathrm{~min}$ of collection at $3000 \mathrm{~g}$ for $10 \mathrm{~min}$, and plasma aliquots were stored at $-80{ }^{\circ} \mathrm{C}$ until analysis. Plasma interleukin- $1 \beta$ (IL-1ß), interleukin-6 (IL-6), and myeloperoxidase (MPO) concentrations were assessed using multiplex assays (Millipore Sigma, Burlington, MA) in duplicate on the MAGPIX multiplex instrument (Luminex Corporation, Austin, TX). Good clinical practices were followed to certify proper storage and daily and long-term quality control of reagents, instruments, and technique. 


\section{Endpoints}

The primary endpoint was the difference in FMD between visit one and visit three (colchicine+XOI). Secondary endpoints included differences in hsCRP, ESR, IL-1 $\beta$, IL-6, and MPO concentrations, as well as NMD, between visit one and visit three. Additional secondary endpoints included differences in all parameters between visit one and visit two (colchicine-only).

\section{Sample size}

For our primary endpoint of FMD, we posited a clinically meaningful change to be a $33-50 \%$ increase from baseline to final (colchicine+XOI) FMD. In a prior study of hyperuricemic individuals without gout, subjects experienced an $81 \%$ increase in FMD after treatment with allopurinol [37]. We calculated that recruiting 30 subjects would give us $83 \%$ power to detect a $60 \%$ improvement from baseline FMD. We also estimated power for our secondary outcome of change in hs-CRP analysis. We anticipated up to a $60 \%$ decline in hs-CRP with colchicine use, based on a study by Nidorf et al., in which non-gout patients with elevated hs-CRP were given colchicine for 30 days [38]. We estimated that we would have $80 \%$ power to detect a $30 \%$ change in CRP from baseline to endpoint with 30 subjects per group using a general linear mixed model. Power for all outcomes was estimated by Monte Carlo simulation using Stata v12.1 (College Station, TX). We recruited 38 subjects to increase our power and to allow for possible withdrawals/ missing data points.

\section{Statistical analyses}

Study data were collected and managed using REDCap (Research Electronic Data Capture) [39]. The demographics and clinical characteristics of subjects were summarized using descriptive statistics as mean \pm standard deviation (SD) (normal distribution) or median [interquartile range] (skewed distribution) for continuous variables, or percentage (counts) for categorical variables. Endpoints were also expressed as mean \pm SD or median [interquartile range]. For comparisons of repeated measures among baseline, colchicine, and colchicine+XOI treatments, analysis of variance (ANOVA) and related-samples Friedman's two-way ANOVA by ranks test were used for normally distributed and skewed endpoints, respectively. For pairwise comparisons of repeated measures between baseline and after intervention, paired $t$ test or related-samples Wilcoxon signed-rank test were used for normally distributed and skewed endpoints, respectively. Statistical significance of a $p$ value $<0.05$ was considered to be relevant. Statistical analyses were conducted in R-statistical package (www.rproject.org) and/or the IBM SPSS Statistics software, version 23 (IBM Corporation, Armonk, New York).
Graphs were generated, and Pearson's correlation coefficient for Fig. 2b was determined, using DeltaGraph 7.1.3, and is presented as mean \pm standard error of the mean, or median [interquartile range].

\section{Results}

\section{Baseline characteristics}

Thirty-eight subjects with gout were enrolled in the study, of whom five (13.2\%) were identified on physical examination as having tophi, and nine (23.7\%) as having radiographic erosions on prior clinical X-rays. At study entry, the median time since receiving a gout diagnosis was 2 years (interquartile range, 0.5-9 years). Twelve subjects $(31.6 \%)$ had previously received ULT (11 allopurinol and 1 febuxostat) (median time since prior ULT = 24 months; interquartile range, 4.5-48 months). Table 1 summarizes the baseline characteristics. All subjects were male. The mean age was $58.6 \pm 13.1$ years, and mean body mass index was $30.5 \pm 4.4 \mathrm{~kg} / \mathrm{m}^{2}$. Consistent with prior literature $[5,6]$, many of the subjects had cardiovascular, renal, and/or metabolic comorbidities and more than a quarter were current smokers.

Thirty-two subjects (84.2\%) were started on allopurinol and two (5.2\%) were started on febuxostat. Four subjects were concurrently enrolled in another study (CSP \#594: Comparative Effectiveness in Gout: Allopurinol vs. Febuxostat; ClinicalTrials.gov identifier NCT02579096) and received either allopurinol or febuxostat in a blinded manner. (Because these subjects received colchicine and an XOI together at the start of the study, they were not available for second visit (colchicine-only) analysis.) Of the subjects started on allopurinol, two were subsequently switched to febuxostat by their physicians, one for a possible hypersensitivity reaction (skin rash) and one because of raised liver enzymes.

\section{Follow-up}

Thirty-two subjects completed the third visit; five subjects were lost to follow-up or failed to comply with treatment, and a single subject experienced arm discomfort after brachial artery function assessment and withdrew from the study. Twenty-nine subjects participated in NMD assessment at visit one, 25 at visit two, and 23 at visit three. Subjects who did not participate in NMD assessment at initiation did so because of personal preference $(n=3)$, medical contraindication to nitroglycerin (systolic BP $<110 \mathrm{mmHg}$ or asymptomatic bradycardia at time of assessment) $(n=2)$, or lack of nitroglycerin availability $(n=4)$. One subject experienced transient hypotension after receiving nitroglycerin on visit one. $\mathrm{He}$ recovered fully, but NMD assessments were not performed at subsequent visits. One subject discontinued 
Table 1 Baseline characteristics

\begin{tabular}{|c|c|}
\hline Characteristic* & Subjects $(n=38)$ \\
\hline Age (years) & $58.6 \pm 13.1$ \\
\hline Body mass index $\left(\mathrm{kg} / \mathrm{m}^{2}\right)$ & $30.5 \pm 4.4$ \\
\hline Years with gout at baseline (median [interquartile range]) & $2.0[0.5-9.0]$ \\
\hline Months since most recent gout attack (median [interquartile range]) & $1[0.5-4]$ \\
\hline Male (\%) & 100 \\
\hline \multicolumn{2}{|l|}{ Race (\%) } \\
\hline White & 39.4 \\
\hline African American & 47.4 \\
\hline Asian & 13.2 \\
\hline \multicolumn{2}{|l|}{ Ethnicity (\%) } \\
\hline Non-Hispanic & 86.9 \\
\hline Hispanic & 13.1 \\
\hline \multicolumn{2}{|l|}{ Co-morbidities (\%) } \\
\hline Chronic kidney disease & 18.4 \\
\hline Hypertension & 68.4 \\
\hline Hyperlipidemia & 55.3 \\
\hline Coronary artery disease & 21.1 \\
\hline Diabetes mellitus & 10.5 \\
\hline \multicolumn{2}{|l|}{ Smoking (\%) } \\
\hline Never & 31.6 \\
\hline Previous & 39.5 \\
\hline Current & 28.9 \\
\hline Bony erosion (\%) & 23.7 \\
\hline Tophus (\%) & 13.2 \\
\hline Creatinine (mg/dL) & $1.13 \pm 0.28$ \\
\hline
\end{tabular}

*Unless otherwise noted, values are expressed as mean \pm standard deviation or \%

colchicine (but continued allopurinol) prior to visit three owing to the prohibitive cost of colchicine.

\section{Serum urate}

Mean sU concentration at baseline was above the upper limit of normal for all subjects and met the standard physiologic definition of hyperuricemia of $>6.8 \mathrm{mg} / \mathrm{dL}$ (mean $9.12 \pm 1.48 \mathrm{mg} / \mathrm{dL}$ ). In overall comparisons, mean $\mathrm{sU}$ concentrations differed across the baseline, colchicine-only, and colchicine+XOI assessments $(p<$ 0.0001) (Table 2). In pairwise comparisons, treatment with colchicine-only for 6 weeks did not change the mean sU concentration $(9.69 \pm 1.50 \mathrm{mg} / \mathrm{dL})$, but after completing colchicine+XOI treatment, all subjects completing the study achieved their pre-specified target $\mathrm{sU}$ concentration (all subjects, $5.08 \pm 0.66 \mathrm{mg} / \mathrm{dL}$; nontophaceous, $5.40 \pm 0.72 \mathrm{mg} / \mathrm{dL}$; tophaceous, $4.50 \pm 0.32$ $\mathrm{mg} / \mathrm{dL}$ ), representing a significant decline in mean $\mathrm{sU}$ concentration from baseline $(p<0.001)$ (Table 2). The mean allopurinol and febuxostat doses at treatment target were $384 \pm 131 \mathrm{mg}$ and $53 \pm 23 \mathrm{mg} /$ day, respectively.
The median [interquartile range] time from initiating ULT (visit 2) to achieving sU target (visit 3) was 21 [1328] weeks for the overall group (for non-tophaceous subjects, 17 [12-27] weeks; for tophaceous patients, 29 [26-42] weeks).

\section{FMD and NMD}

Mean FMD at baseline was $1.93 \% \pm 3.29$, numerically lower than that reported in non-gout control populations $[25,36,40,41]$. Only $16 \%$ of subjects had a baseline FMD value greater than our laboratory norm for healthy controls. In overall comparisons FMD did not differ across the baseline, colchicine-only, and colchicine + XOI assessments $(p=0.40)$ (Table 2). In pairwise comparisons, treatment with colchicine-only for 6 weeks numerically improved the mean FMD $(2.33 \% \pm 2.95)$ from baseline $(p=0.72)$ (relative increase $20.7 \%$ from baseline), and after completing colchicine+XOI treatment, there was a significantly higher mean FMD $(3.04 \% \pm 2.36)$ with a $58 \%$ relative increase from baseline $(p=0.03)$ (Fig. 1a). 
Table 2 Overall changes in endpoints across treatment steps

\begin{tabular}{|c|c|c|c|c|}
\hline \multirow[t]{2}{*}{ Outcome } & \multicolumn{4}{|c|}{ Mean \pm SD or median [interquartile range] $N$ (missing \%) } \\
\hline & Pre-treatment at baseline (visit 1) & Colchicine (visit 2) & Colchicine + XOI (visit 3) & $p$ value* ${ }^{*}$ \\
\hline \multirow[t]{2}{*}{$\mathrm{sU}(\mathrm{mg} / \mathrm{dL})$} & $9.12 \pm 1.48$ & $9.69 \pm 1.50$ & $5.08 \pm 0.66$ & $<0.0001$ \\
\hline & $38(0 \%)$ & $31(18.4 \%)$ & $32(15.8 \%)$ & \\
\hline \multirow[t]{2}{*}{ FMD (\% dilation) } & $1.93 \pm 3.29$ & $2.33 \pm 2.95$ & $3.04 \pm 2.36$ & 0.40 \\
\hline & $38(0 \%)$ & $36(5.3 \%)$ & $31(18.4 \%)$ & \\
\hline \multirow[t]{2}{*}{ NMD (\% dilation) } & $17.45 \pm 9.55$ & $17.98 \pm 6.07$ & $17.25 \pm 6.17$ & 0.82 \\
\hline & $29(23.7 \%)$ & $25(34.2 \%)$ & $23(39.5 \%)$ & \\
\hline \multirow[t]{2}{*}{ hsCRP (mg/L) } & $4.28 \pm 0.46$ & $3.9 \pm 0.53$ & $3.0 \pm 0.34$ & 0.12 \\
\hline & $36(5.3 \%) \mathrm{s}$ & $32(15.8 \%)$ & $32(15.8 \%)$ & \\
\hline \multirow[t]{2}{*}{$\operatorname{ESR}(\mathrm{mm} / \mathrm{H})$} & $14.85 \pm 8.72$ & $12.90 \pm 11.84$ & $10.81 \pm 6.59$ & 0.03 \\
\hline & $36(5.3 \%)$ & $29(23.7 \%)$ & $31(18.4 \%)$ & \\
\hline \multirow[t]{2}{*}{$\mathrm{IL}-1 \beta(\mathrm{pg} / \mathrm{mL})$} & $2.60[1.99-3.14]$ & $2.64[1.64-3.42]$ & $2.05[1.35-2.82]$ & $0.01^{* *}$ \\
\hline & $34(11 \%)$ & $32(16 \%)$ & $28(26 \%)$ & \\
\hline \multirow[t]{2}{*}{ IL-6 (pg/mL) } & $5.23[3.84-24.74]$ & $6.00[2.65-32.66]$ & $4.69[2.22-14.90]$ & $0.02^{* *}$ \\
\hline & $34(11 \%)$ & $32(16 \%)$ & $28(26 \%)$ & \\
\hline \multirow[t]{2}{*}{$\mathrm{MPO}(\mathrm{ng} / \mathrm{mL})$} & $160[63-258]$ & $150[83-317]$ & $182[69-278]$ & $0.87^{* *}$ \\
\hline & $34(11 \%)$ & $32(16 \%)$ & $28(26 \%)$ & \\
\hline
\end{tabular}

$s U$ serum urate, FMD flow-mediated dilation, $N M D$ nitrate-mediated dilation, $h s C R P$ high-sensitivity C-reactive protein, ESR erythrocyte sedimentation rate, IL- $\beta$ interleukin-1 $\beta, I L-6$ interleukin $6, M P O$ myeloperoxidase

${ }^{*} p$ values by univariate mixed-effect model ANOVA except where double asterisk $\left({ }^{* *}\right)$ indicates related-samples Friedman's two-way ANOVA by ranks test
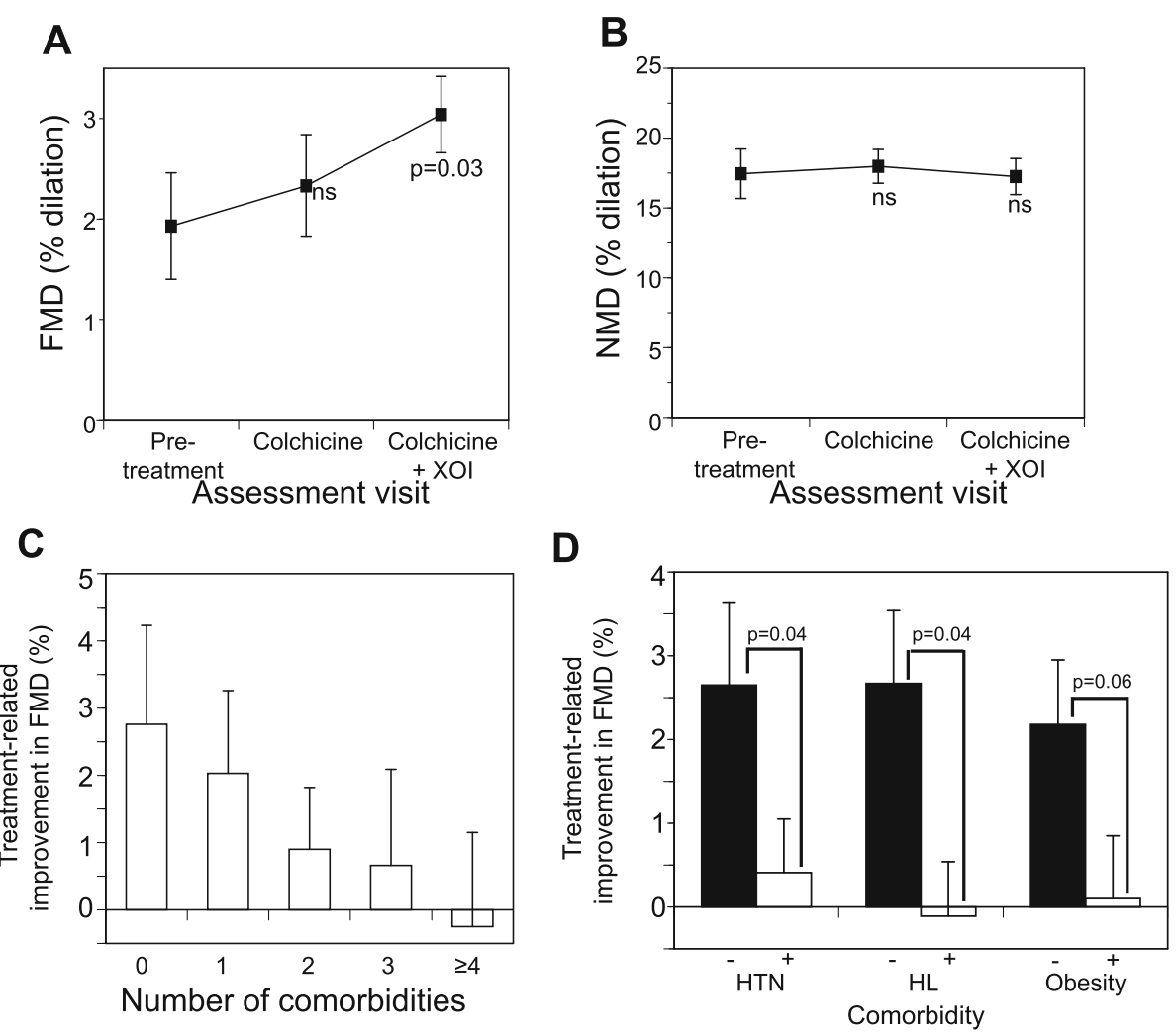

Fig. 1 Impact of colchicine alone and colchicine+XOI on endothelial-dependent and endothelial-independent arterial responsiveness. a Flowmediated dilation (FMD). b Nitrate-mediated dilation (NMD). c Relationship between number of co-morbidities and FMD improvement in response to colchicine+XOI. $\mathbf{d}$ Relationship between presence and absence of specific co-morbidities and FMD responsiveness to colchicine+XOI. HTN, hypertension; HLD, hyperlipidemia. Data shown are mean \pm SEM 
Mean NMD at baseline was $17.45 \% \pm 9.55$, numerically lower than that reported in non-gout control populations $[34,40]$. Only $27 \%$ of subjects had a baseline NMD value greater than our laboratory norm for healthy controls. In contrast to FMD, NMD showed no improvement after treatment overall, or in pairwise comparisons (Table 2, Fig. 1b). Pairwise comparisons between colchicine-only and colchicine $+\mathrm{XOI}$ assessments were not significant for either FMD $(p=0.12)$ or NMD $(p=0.20)$.

\section{Impact of co-morbidities on FMD response}

Overall, there was an inverse relationship between the total number of cardiovascular co-morbidities (diabetes, hypertension, hyperlipidemia, coronary artery disease, chronic kidney disease, and obesity) and the improvement of FMD in response to colchicine+XOI, such that patients with fewer comorbidities were more likely to experience FMD improvement (Fig. 1c). To further examine the role of comorbidities, we compared FMD results in patients with versus without the most common comorbidities in the population. Subjects without either hypertension or hyperlipidemia experienced significant post-treatment improvements in FMD, compared to subjects with these individual comorbidities (Fig. 1d). Similarly, non-obese subjects (body mass index $<30 \mathrm{~kg} / \mathrm{m}^{2}$ ) experienced greater numerical improvement in FMD compared with obese subjects (Fig. 1d). The numbers of subjects with diagnosed coronary artery disease, chronic kidney disease, or diabetes mellitus were too small to permit similar comparisons. In contrast to FMD, the presence/absence and number of comorbidities had no consistent impact on NMD response to colchicine+XOI (data not shown).

\section{Inflammatory markers}

Mean hsCRP concentration at baseline was elevated above the clinical laboratory normal range $(4.28 \pm 0.46$ $\mathrm{mg} / \mathrm{L})$. Overall, mean hsCRP concentrations did not differ across the baseline, colchicine-only, and colchicine+ XOI assessments $(p=0.12)$ (Table 2). In pairwise comparison, treatment with colchicine for 6 weeks numerically lowered the mean hsCRP concentration $(3.9 \pm 0.53$ $\mathrm{mg} / \mathrm{L})$ from baseline $(8.9 \%$ relative reduction; $p=0.73)$ (Fig. 2a). After completing colchicine+XOI treatment, there was a significant further decline in mean hsCRP concentration $(3.0 \pm 0.34 \mathrm{mg} / \mathrm{L})$ with a relative $30 \%$
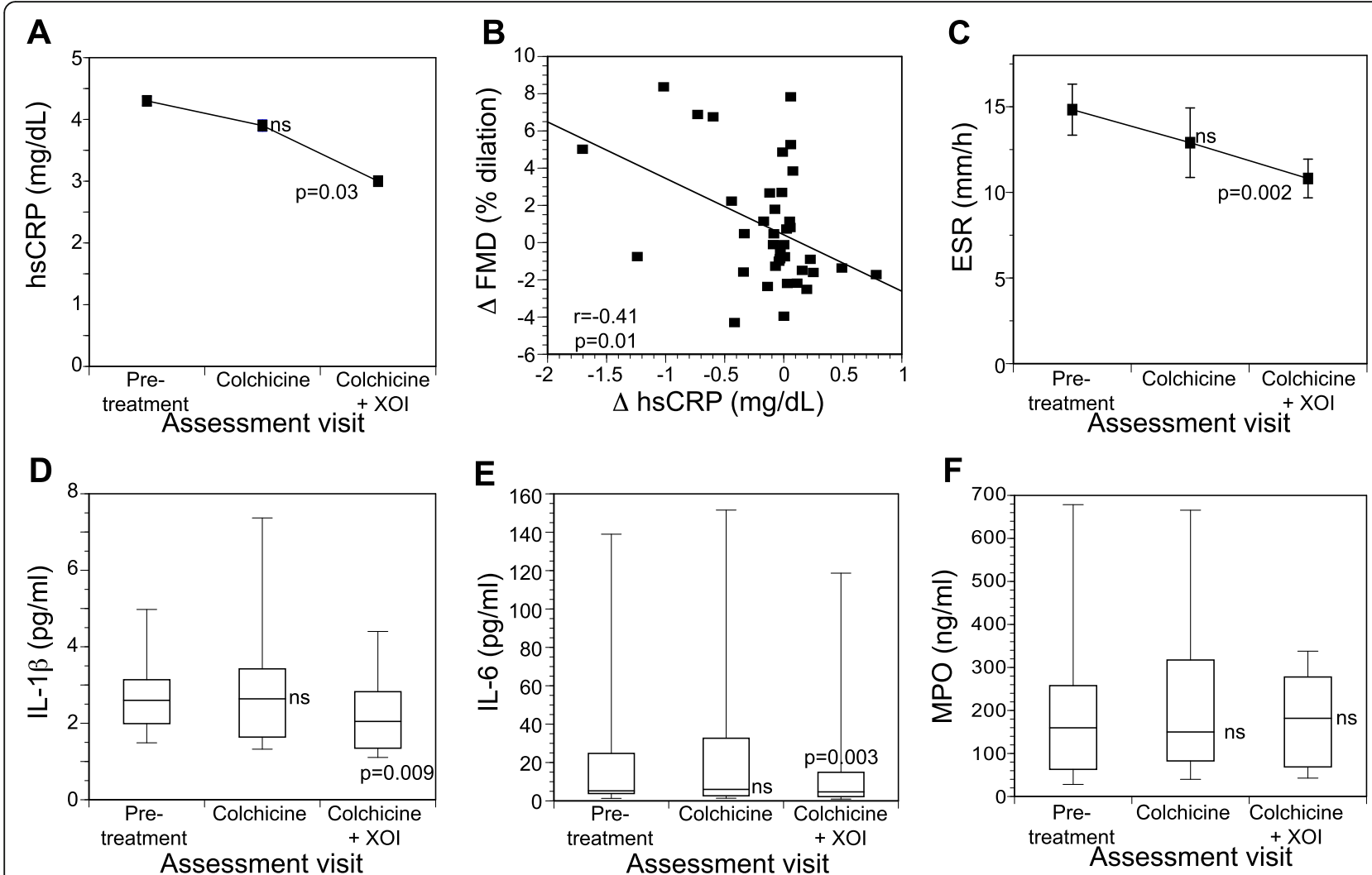

Fig. 2 Impact of colchicine alone and colchicine plus a xanthine oxidase inhibitor (colchicine+XOI) on systemic inflammation in gout subjects. a High-sensitivity C-reactive protein (hsCRP). b Regression analysis showing relationship between changes in hsCRP and FMD in response to colchicine+XOI. c Erythrocyte sedimentation rate (ESR). $\mathbf{d}$ IL-1 $\beta$. e IL-6. f Myeloperoxidase (MPO). Data shown are mean \pm SEM for $\mathbf{a}, \mathbf{c}$, and median/interquartile range for $\mathbf{d}-\mathbf{f}$ 
reduction from baseline $(p=0.03)$ (Fig. 2a). Declines in hsCRP between the colchicine-only and colchicine+XOI assessments were borderline significant $(p=0.06)$. Improvement (decline) in hsCRP correlated moderately with improvement (increase) in FMD $(\mathrm{R}=-0.41, p=$ 0.01) (Fig. 2b).

Mean ESR concentration at baseline $(14.85 \pm 8.72 \mathrm{~mm} /$ h) was not elevated above the upper limit of normal. Nonetheless, mean ESR concentration differed across the baseline, colchicine-only, and colchicine+XOI assessments $(p=0.03)$ (Table 2). In pairwise comparisons, treatment with colchicine-only for 6 weeks numerically lowered the mean ESR concentration $(12.90 \pm 11.84 \mathrm{~mm} / \mathrm{h})$ with a relative $13 \%$ reduction from baseline $(p=0.43)$ (Fig. 2c). After completing colchicine $+\mathrm{XOI}$ treatment, there was a significant decline in mean ESR concentration (10.81 \pm $6.59 \mathrm{~mm} / \mathrm{h}$ ) with a relative $27 \%$ reduction from baseline $(p=0.002)$. Declines in ESR between the colchicine-only and colchicine $+\mathrm{XOI}$ assessments were borderline significant $(p=0.07)$ (Fig. 2c).

Median IL-1 $\beta$ and IL- 6 concentrations, but not MPO concentration, differed across the baseline, colchicineonly, and colchicine+XOI assessments (Table 2). In pairwise comparisons, treatment with colchicine-only for 6 weeks did not change the median IL-1 $\beta(p=0.91)$ or median IL-6 $(p=0.83)$ concentrations, but after completing colchicine+XOI treatment, there were significant decreases in both IL-1 $\beta$ (19.5\% relative reduction; $p=$ $0.009)$ and IL-6 $(18.8 \%$ relative reduction; $p=0.003)$ concentrations compared with baseline (Fig. $2 \mathrm{~d}$,e). Declines in median IL-1 $\beta$ and IL- 6 concentrations between the colchicine-only and colchicine $+\mathrm{XOI}$ assessments were significant $(p=0.02$ for each analysis). Neither colchicine-only $(p=0.48)$ nor colchicine+XOI $(p=0.63)$ reduced median MPO concentrations compared with baseline (Fig. 2f).

In a sensitivity analysis, exclusion of the four patients enrolled in a parallel trial did not change the overall results or conclusions for either FMD/NMD or inflammatory markers (data not shown).

\section{Discussion}

Our findings indicate that initiating guidelineconcordant gout treatment with colchicine+XOI to target $\mathrm{sU}$ concentration results in significantly increased brachial artery flow-mediated vasodilation along with significant reductions in intercritical bloodstream hsCRP, ESR, IL-1 $\beta$, and IL- 6 concentrations, indicating that colchicine+XOI enhances vascular endothelial function and reduces baseline systemic inflammation in gout patients. Since endothelial dysfunction, elevated hsCRP, IL- $1 \beta$, and IL- 6 concentrations have all been associated with increased cardiovascular risk [26-28, 38, 42-44], and since lowering of hsCRP and IL-6 via anti-IL-1 $\beta$ strategies is associated with reduced rates of major adverse cardiovascular events $[45,46]$, these data suggest that gout treatment with colchicine+XOI may lower cardiovascular risk. Concentrations of MPO, a marker of neutrophil activation that is also associated with increased cardiovascular risk [47], were unaffected by colchicine $+\mathrm{XOI}$ treatment, indicating that not all aspects of inflammation may be modulated with initiating treatment in gout.

The ability of colchicine+XOI to improve endothelial function in our study is consistent with a prior study of individuals with asymptomatic hyperuricemia (hyperuricemia in the absence of gout), in which treatment with allopurinol $300 \mathrm{mg}$ daily resulted in significant improvement in FMD [37]. However, the ability of XOI to improve endothelial function has not been previously reported in gout patients, the population most likely to receive these medications. Whether the benefit of xanthine oxidase inhibition on FMD is a consequence of $s \mathrm{U}$ lowering remains uncertain; some investigators have suggested that the vascular benefits of allopurinol may be due instead to its ability to reduce oxidant load [48]. Given that the current study was based on a treat-to-sU-target observational design in which all patients achieved a urate level $\leq 6.0 \mathrm{mg} / \mathrm{dL}$, we cannot distinguish between the impact of sU lowering and any other effect of XOI treatment. Patients in our study also demonstrated a small albeit non-significant increase in FMD after colchicine alone, raising the possibility of a separate or additional colchicine effect.

Beyond improvement in FMD after colchicine+XOI treatment, we observed differences in the degree of FMD improvement based on the status of cardiovascular-associated comorbidities. Subjects with fewer cardiovascular comorbidities, and specifically, those without hypertension or hyperlipidemia, were more likely to experience FMD improvement in response to gout treatment than those with these conditions. These data suggest that established cardiovascular disease may limit the ability of the vasculature to respond to initiation of gout therapy and may be consistent with observations that urate lowering in hyperuricemic adolescents resulted in improvement in newonset essential hypertension [49], whereas urate lowering in hyperuricemic adults with stage 3 chronic kidney disease was not similarly effective [50]. Current treatment guidelines recommend that chronic gout treatment be considered after multiple attacks, or after one attack in the setting of comorbidities. In this context, our data potentially argue for the importance of stillearlier initiation of gout management, prior to the establishment of comorbidities. Unfortunately, even under current, less-stringent guidelines, the quality of care remains poor in the general population of gout sufferers [51]. 
In contrast to FMD, we observed no improvement in NMD either after colchicine alone, or after colchicine+ XOI treatment. Thus, although NMD was impaired, and although several studies suggest that urate may interfere with smooth muscle function $[25,52,53]$, it does not appear that initiating gout treatment can reverse established smooth muscle impairment as measured by exogenous nitrate administration, at least after shortterm treatment. The absence of treatment-related improvement in NMD may suggest that our FMD findings are attributable to increased bioavailability of endogenous nitric oxide, or other endothelium-derived vasodilator substances in vascular smooth muscle.

Whether the decrease in inflammatory markers that we observed after colchicine+XOI was due to extended exposure to colchicine, to the impact of XOI, or both cannot be determined based on the study design. In this context, it is interesting to note that Ives et al. have reported that xanthine oxidoreductase activity (the target of XOIs) can directly activate the NLRP3 inflammasome independent of urate generation, and that XOIs may therefore have urate-independent anti-inflammatory effects [54]. It was unexpected that initial treatment with colchicine alone did not result in significant reductions in inflammatory markers, since Nidorf et al. previously demonstrated that colchicine $0.5 \mathrm{mg}$ twice daily significantly lowers hsCRP concentrations among non-gout patients with coronary artery disease after 4 weeks [38]. However, our study population was small, and we did observe non-significant decrements in some inflammatory markers after treatment with colchicine alone. It is possible that longer exposure, or assessment in a larger subject sample, would have revealed an independent effect of colchicine. It is also possible that gout patients are more resistant to the anti-inflammatory actions of colchicine compared to individuals without gout. Importantly, we observed an inverse correlation between hsCRP and FMD improvement, suggesting a link between inflammation and endothelial function. In contrast to 2012 guidelines, which specified a minimum of 6 months, 2020 ACR treatment guidelines suggest that prophylaxis be continued for a period of between 3 and 6 months $[14,15]$. Whether ongoing use of colchicine, beyond the recommended prophylactic period, would have a durable cardiovascular benefit is a question raised, but not answered, by our study. Several other studies, though, do suggest a cardiovascular benefit of colchicine use in both the gout population and non-gout coronary artery disease populations [17, 18, 55]. Our studies also did not address the possible use of either NSAIDs (endorsed in both the 2012 and 2020 ACR gout treatment guidelines) or glucocorticoids (endorsed in the 2020 guidelines) as prophylaxis [14, 15]. We chose to study colchicine because of accumulating evidence supporting its cardiovascular benefit. In contrast, longterm use of both NSAIDs and glucocorticoids has been associated with increased cardiovascular risk [56]. However, such long-term risk does not preclude the possibility that initial prophylaxis with either of these two antiinflammatory classes could have beneficial effect on FMD. Separate studies would be required to resolve this issue.

The strengths of this study include our use of a staggered treatment schedule, which allowed us to assess the initial effects of colchicine in isolation. Our observational design allowed treating physicians to select the XOI of their choice, reflecting real-world use and facilitating enrollment. Limitations of this study include our reliance on treating physicians to order laboratory studies, which led to cases of missing laboratory data. The fact that most patients received allopurinol was consistent with current US Food and Drug Administration recommendations [57], but prevented us from assessing the effect of febuxostat, a question of interest given recent reports that patients receiving febuxostat may have higher rates of cardiovascular and all-cause mortality compared with patients receiving allopurinol [58]. Moreover, our lack of an untreated control population may have limited our sensitivity to ascertain treatment-related differences. Our treat-to-target strategy was consistent with guidelinebased management but resulted in a variable time period among patients between the second (colchicine-only) and third (colchicine+XOI) assessment. Our all-male subject population reflected the fact that we were recruiting for largely a male disease (gout) in a largely male hospital population (Veterans Affairs) but did not permit us to definitively extrapolate the effect of treatment on female gout patients. Even though a single technologist performed all FMD/NMD studies and the results were read by a blinded cardiologist, there likely remains considerable variability in FMD measurement. Our study population was limited, but establishes a context for larger, controlled studies to clarify these issues.

\section{Conclusions}

In conclusion, initiating guidelines-concordant gout treatment with colchicine+XOI led to improved endothelial function, particularly among patients with fewer established cardiovascular co-morbidities. Colchicine+XOI also led to a decline in markers of systemic inflammation. Given that both impaired endothelial function and systemic inflammation are risk factors for adverse CV outcomes, these observations suggest that initiating guideline-concordant gout treatment may lower the risk for adverse $\mathrm{CV}$ outcomes through intravascular mechanisms.

\section{Abbreviations}

ACR: American College of Rheumatology; EULAR: European League Against Rheumatism; ULT: Urate-lowering therapy; XOI: Xanthine-oxidase inhibitor; sU: Serum urate; FMD: Flow-mediated dilation; NMD: Nitrate-mediated 
dilation; hsCRP: High-sensitivity C-reactive protein; ESR: Erythrocyte sedimentation rate; IL-1 B: Interleukin-1 B; IL-6: Interleukin-6; MPO: Myeloperoxidase; SD: Standard deviation; SE: Standard error; ANOVA: Analysis of variance

\section{Acknowledgements}

The authors thank Irina Dektiarev for performing FMD/NMD assessments and Drs. Jonathan Samuels, Cesar Fors, Stephen Bernstein, Adey Berhanu, and Sabina Sandigursky for referring their patients for the study and agreeing to initiate urate-lowering therapy within the parameters of our suggested protocol. We thank Dr. Bruce Cronstein for helpful input.

\section{Authors' contributions}

MT participated in study design, obtaining funding, patient recruitment and assessment, data analysis and interpretation, and manuscript conception and revision. BS participated in study design (including provision of cardiovascular expertise) and assisted with patient safety monitoring, data analysis and interpretation, and with the review and revision of the final manuscript. CO contributed to study design (particularly providing statistical expertise), analysis and interpretation of data, and manuscript revision. TFI participated in study design, patient interview and recruitment, acquisition of data, and initial data analyses. AGR participated in study design, patient interview and recruitment and acquisition of data, presented the data initially in abstract form, and participated in writing the initial draft of the manuscript. VCP participated in study design and was responsible for overall study management; she performed patient interview and recruitment, collected serum and plasma samples and oversaw FMD/NMD procedures, and contributed to manuscript drafting/revision and data analysis. FC participated in laboratory analysis and manuscript development and revision. DB participated in study design, patient interview and recruitment and acquisition of data, presented the data initially in abstract form, and participated in developing the manuscript. DL participated in patient recruitment and follow-up and in developing the manuscript. SK was responsible for initial study conception, proposal and design (principal investigator, including development of grant and obtaining funding, as well as gout expertise), acquisition of data, patient interview and recruitment, and data analysis and interpretation and was a principal writer of the manuscript. SDK participated in study design (including grant-writing and obtaining funding, as well as brachial artery assessment expertise), data analysis and interpretation, and manuscript conception and revision. MHP was responsible for initial study conception, proposal, and design (principal investigator, including development of grant and obtaining funding, as well as gout expertise), acquisition of data, patient interview and recruitment, and data analysis and interpretation and wrote the first draft of the manuscript. All authors read and approved the final manuscript.

\section{Funding}

The study was funded in part by a New York State Empire Clinical Investigator Grant (to SK, MHP and SDK), by an Investigator Award from the Rheumatology Research Foundation (SK), and by a pilot award from the NYU Clinical and Translational Science Institute (to MT) supported by a Clinical and Translational Science Award (1UL1TR001445) to New York University from the National Center for the Advancement of Translational Science, National Institutes of Health. MHP and SDK receive salary support from that same award (1UL1TR001445). BS was supported in part by the Biomedical Laboratory Research and Development Service of the VA Office of Research and Development (iK2CX001074), United States Department of Veterans Affairs, and NIH NHLBI (R01HL146206).

\section{Availability of data and materials}

Data is available through the corresponding author.

\section{Ethics approval and consent to participate}

This study was approved by the Institutional Review Boards of NYU Langone Medical Center, Bellevue Hospital, and the New York Harbor Health Care System of the Department of Veterans Affairs. All subjects provided signed consent for participation.

\section{Consent for publication}

Not applicable.

\section{Competing interests}

The authors declare that they have no direct competing interests relating to this study. For the purposes of full transparency, they offer the following disclosures. MT: nothing to disclose. BS: Philips Volcano Advisory Board; Radux Medical Advisory Board; Terumo Medical Consultant. CO. nothing to disclose. TFI: nothing to disclose. AGR: nothing to disclose. VCP: nothing to disclose. FC: nothing to disclose. DB: nothing to disclose. DL: nothing to disclose. SK: Investigator-initiated grant from Hikma Pharmaceuticals. SDK: nothing to disclose. MHP: Consultancies for Horizon Pharma, and Sobi, and investigator-initiated grants from Horizon Pharma and Hikma Pharmaceuticals.

\section{Author details}

${ }^{1}$ Section of Rheumatology, VA New York Harbor Health Care System, New York, NY, USA. ${ }^{2}$ Division of Rheumatology, NYU Grossman School of Medicine, NYU Hospital for Joint Diseases Suite 1410, 301 East 17th Street, New York, NY 10003, USA. ${ }^{3}$ Section of Cardiology, VA New York Harbor Health Care System, New York, NY, USA. ${ }^{4}$ Division of Cardiology, Department of Medicine, NYU Grossman School of Medicine, New York, NY, USA.

${ }^{5}$ Division of Biostatistics, Department of Population Health, NYU Grossman School of Medicine, New York, NY, USA.

Received: 2 April 2020 Accepted: 2 July 2020

Published online: 11 July 2020

\section{References}

1. Chen-Xu M, Yokose C, Rai SK, Pillinger MH, Choi HK. Contemporary prevalence of gout and hyperuricemia in the United States and decadal trends: the National Health and Nutrition Examination Survey, 2007-2016. Arthritis Rheumatol. 2019;71(6):991-9.

2. Elfishawi MM, Zleik N, Kvrgic Z, Michet CJ Jr, Crowson CS, Matteson EL, Bongartz $\mathrm{T}$. The rising incidence of gout and the increasing burden of comorbidities: a population-based study over 20 years. J Rheumatol. 2018; 45(4):574-9.

3. Choi HK, Curhan G. Independent impact of gout on mortality and risk for coronary heart disease. Circulation. 2007;116(8):894-900.

4. Christensen JL, Yu W, Tan S, Chu A, Vargas F, Assali M, Shah NR, Reginato AM, Wu WC, Choudhary G, et al. Gout is associated with increased coronary artery calcification and adverse cardiovascular outcomes. JACC CardiovasC Imaging. 2019;13(3):884-86.

5. Zhu Y, Pandya BJ, Choi HK. Comorbidities of gout and hyperuricemia in the US general population: NHANES 2007-2008. Am J Med. 2012;125(7):679687.e671.

6. Keenan RT, O'Brien WR, Lee KH, Crittenden DB, Fisher MC, Goldfarb DS, Krasnokutsky S, Oh C, Pillinger MH. Prevalence of contraindications and prescription of pharmacologic therapies for gout. Am J Med. 2011;124(2): 155-63.

7. Disveld IJM, Fransen J, Rongen GA, Kienhorst LBE, Zoakman S, Janssens H, Janssen M. Crystal-proven gout and characteristic gout severity factors are associated with cardiovascular disease. J Rheumatol. 2018;45(6):858-63.

8. Clarson LE, Hider SL, Belcher J, Heneghan C, Roddy E, Mallen CD. Increased risk of vascular disease associated with gout: a retrospective, matched cohort study in the UK clinical practice research datalink. Ann Rheum Dis. 2015;74(4):642-7.

9. Pagidipati NJ, Hess CN, Clare RM, Akerblom A, Tricoci P, Wojdyla D, Keenan RT, James S, Held C, Mahaffey KW, et al. An examination of the relationship between serum uric acid level, a clinical history of gout, and cardiovascular outcomes among patients with acute coronary syndrome. Am Heart J. 2017;187:53-61.

10. Hansson GK. Inflammation, atherosclerosis, and coronary artery disease. N Engl J Med. 2005;352(16):1685-95.

11. Yip K, Cohen RE, Pillinger MH. Asymptomatic hyperuricemia: is it really asymptomatic? Curr Opin Rheumatol. 2020;32(1):71-9.

12. Khanna D, Fitzgerald JD, Khanna PP, Bae S, Singh MK, Neogi T, Pillinger MH, Merill J, Lee S, Prakash S, et al. 2012 American College of Rheumatology guidelines for management of gout. Part 1: systematic nonpharmacologic and pharmacologic therapeutic approaches to hyperuricemia. Arthritis Care Res (Hoboken). 2012;64(10):1431-46.

13. Richette P, Doherty M, Pascual E, Barskova V, Becce F, Castañeda-Sanabria J, Coyfish M, Guillo S, Jansen TL, Janssens H, et al. 2016 updated EULAR 
evidence-based recommendations for the management of gout. Ann Rheum Dis. 2017;76(1):29-42.

14. FitzGerald JD, Dalbeth N, Mikuls T, Brignardello-Petersen R, Guyatt G, Abeles AM, Gelber AC, Harrold LR, Khanna D, King C, et al. 2020 American College of Rheumatology Guideline for the Management of Gout. Arthritis Rheumatol. 2020;72(6):879-95.

15. Khanna D, Khanna PP, Fitzgerald JD, Singh MK, Bae S, Neogi T, Pillinger MH, Merill J, Lee S, Prakash S, et al. 2012 American College of Rheumatology guidelines for management of gout. Part 2: therapy and antiinflammatory prophylaxis of acute gouty arthritis. Arthritis Care Res (Hoboken). 2012; 64(10):1447-61.

16. Crittenden DB, Lehmann RA, Schneck L, Keenan RT, Shah B, Greenberg JD, Cronstein BN, Sedlis SP, Pillinger MH. Colchicine use is associated with decreased prevalence of myocardial infarction in patients with gout. J Rheumatol. 2012:39(7):1458-64.

17. Solomon DH, Liu CC, Kuo IH, Zak A, Kim SC. Effects of colchicine on risk of cardiovascular events and mortality among patients with gout: a cohort study using electronic medical records linked with Medicare claims. Ann Rheum Dis. 2016:75(9):1674-9.

18. Nidorf SM, Eikelboom JW, Thompson PL. Colchicine for secondary prevention of cardiovascular disease. Curr Atheroscler Rep. 2014;16(3):391.

19. Tardif JC, Kouz S, Waters DD, OF B, Diaz R, Maggioni AP, Pinto FJ, Ibrahim R, Gamra H, Kiwan GS, et al. Efficacy and safety of low-dose colchicine after myocardial infarction. N Engl J Med. 2019;381(26):2497-505.

20. Singh JA, Ramachandaran R, Yu S, Curtis JR. Allopurinol use and the risk of acute cardiovascular events in patients with gout and diabetes. BMC Cardiovasc Disord. 2017;17(1):76.

21. Dubreuil M, Zhu Y, Zhang Y, Seeger JD, Lu N, Rho YH, Choi HK. Allopurinol initiation and all-cause mortality in the general population. Ann Rheum Dis. 2015;74(7):1368-72.

22. Goicoechea M, de Vinuesa SG, Verdalles U, Ruiz-Caro C, Ampuero J, Rincon A, Arroyo D, Luno J. Effect of allopurinol in chronic kidney disease progression and cardiovascular risk. Clin J Am Soc Nephrol. 2010;5(8):1388-93.

23. Larsen KS, Pottegard A, Lindegaard HM, Hallas J. Effect of allopurinol on cardiovascular outcomes in hyperuricemic patients: a cohort study. Am J Med. 2016;129(3):299-306 e292.

24. Ridker PM, Everett BM, Thuren T, MacFadyen JG, Chang WH, Ballantyne C, Fonseca F, Nicolau J, Koenig W, Anker SD, et al. Antiinflammatory therapy with canakinumab for atherosclerotic disease. N Engl J Med. 2017;377(12):1119-31.

25. Krasnokutsky S, Romero AG, Bang D, Pike VC, Shah B, Igel TF, Dektiarev I, Guo Y, Zhong J, Katz SD, et al. Impaired arterial responsiveness in untreated gout patients compared with healthy non-gout controls: association with serum urate and C-reactive protein. Clin Rheumatol. 2018;37(7):1903-11.

26. Yeboah J, Folsom AR, Burke GL, Johnson C, Polak JF, Post W, Lima JA, Crouse JR, Herrington DM. Predictive value of brachial flow-mediated dilation for incident cardiovascular events in a population-based study: the multi-ethnic study of atherosclerosis. Circulation. 2009;120(6):502-9.

27. Yeboah J, Crouse JR, Hsu FC, Burke GL, Herrington DM. Brachial flowmediated dilation predicts incident cardiovascular events in older adults: the Cardiovascular Health Study. Circulation. 2007;115(18):2390-7.

28. Villano A, Mencarelli E, Melita V, Rizzi A, Lamendola P, De Vita A Manfredonia L, Ravenna SE, Pitocco D, Lanza GA, et al. Endothelial dysfunction and cardiovascular outcome in asymptomatic patients with type 2 diabetes: a pilot study. Diabetes Metab Res Rev. 2020;36(1):e3215.

29. Irace C, De Rosa S, Tripolino C, Ambrosio G, Covello C, Abramo E, Carallo C, Mongiardo A, Spaccarotella C, Torella D, et al. Delayed flow-mediated vasodilation and critical coronary stenosis. J Investig Med. 2018;66(5):1-7.

30. Choi Y-J, Yoon Y, Lee K-Y, Hien TT, Kang KW, Kim K-C, Lee J, Lee M-Y, Lee SM, Kang D-H, et al. Uric acid induces endothelial dysfunction by vascular insulin resistance associated with the impairment of nitric oxide synthesis. FASEB J. 2014;28(7):3197-204

31. Khosla UM, Zharikov S, Finch JL, Nakagawa T, Roncal C, Mu W, Krotova K, Block ER, Prabhakar S, Johnson RJ. Hyperuricemia induces endothelial dysfunction. Kidney Int. 2005;67(5):1739-42.

32. Neogi T, Jansen TL, Dalbeth N, Fransen J, Schumacher HR, Berendsen D, Brown M, Choi H, Edwards NL, Janssens HJ, et al. 2015 Gout classification criteria: an American College of Rheumatology/European League Against Rheumatism collaborative initiative. Ann Rheum Dis. 2015;74(10):1789-98.

33. Zheng H, Cable R, Spencer B, Votto N, Katz SD. Iron stores and vascular function in voluntary blood donors. Arterioscler Thromb Vasc Biol. 2005; 25(8):1577-83.
34. Zheng H, Patel M, Cable R, Young L, Katz SD. Insulin sensitivity, vascular function, and iron stores in voluntary blood donors. Diabetes Care. 2007; 30(10):2685-9.

35. Corretti MC, Anderson TJ, Benjamin EJ, Celermajer D, Charbonneau F, Creager MA, Deanfield J, Drexler H, Gerhard-Herman M, Herrington D, et al. Guidelines for the ultrasound assessment of endothelialdependent flow-mediated vasodilation of the brachial artery: a report of the International Brachial Artery Reactivity Task Force. J Am Coll Cardiol. 2002:39(2):257-65.

36. Jelani QU, Norcliffe-Kaufmann L, Kaufmann H, Katz SD. Vascular endothelial function and blood pressure regulation in afferent autonomic failure. Am J Hypertens. 2015;28(2):166-72.

37. Kanbay M, Huddam B, Azak A, Solak Y, Kadioglu GK, Kirbas I, Duranay M, Covic A, Johnson RJ. A randomized study of allopurinol on endothelial function and estimated glomular filtration rate in asymptomatic hyperuricemic subjects with normal renal function. Clin J Am Soc Nephrol. 2011;6(8):1887-94.

38. Nidorf M, Thompson PL. Effect of colchicine ( $0.5 \mathrm{mg}$ twice daily) on highsensitivity C-reactive protein independent of aspirin and atorvastatin in patients with stable coronary artery disease. Am J Cardiol. 2007;99(6):805-7.

39. Harris PA, Taylor R, Thielke R, Payne J, Gonzalez N, Conde JG. Research electronic data capture (REDCap)--a metadata-driven methodology and workflow process for providing translational research informatics support. J Biomed Inform. 2009:42(2):377-81.

40. Jelani QU, Harchandani B, Cable RG, Guo Y, Zhong H, Hilbert T, Newman JD, Katz SD. Effects of serial phlebotomy on vascular endothelial function: results of a prospective double-blind randomized study. Cardiovasc Ther. 2018;36(6):e12470

41. Schroeder EC, Lane-Cordova AD, Ranadive SM, Baynard T, Fernhall B. Influence of fitness and age on the endothelial response to acute inflammation. Exp Physiol. 2018;103(6):924-31.

42. Ridker PM, Buring JE, Cook NR, Rifai N. C-reactive protein, the metabolic syndrome, and risk of incident cardiovascular events: an 8-year follow-up of 14719 initially healthy American women. Circulation. 2003:107(3):391-7.

43. Ridker PM, Rifai N, Stampfer MJ, Hennekens CH. Plasma concentration of interleukin- 6 and the risk of future myocardial infarction among apparently healthy men. Circulation. 2000;101(15):1767-72.

44. Galea J, Armstrong J, Gadsdon P, Holden H, Francis SE, Holt CM. Interleukin1 beta in coronary arteries of patients with ischemic heart disease. Arterioscler Thromb Vasc Biol. 1996;16(8):1000-6.

45. Ridker PM. Moving beyond JUPITER: will inhibiting inflammation reduce vascular event rates? Curr Atheroscler Rep. 2013;15(1):295.

46. Ridker PM, MacFadyen JG, Everett BM, Libby P, Thuren T, Glynn RJ, Group $\mathrm{CT}$. Relationship of C-reactive protein reduction to cardiovascular event reduction following treatment with canakinumab: a secondary analysis from the CANTOS randomised controlled trial. Lancet. 2018;391(10118):319-28.

47. Baldus S, Heeschen C, Meinertz T, Zeiher AM, Eiserich JP, Munzel T, Simoons ML, Hamm CW. Myeloperoxidase serum levels predict risk in patients with acute coronary syndromes. Circulation. 2003;108(12):1440-5.

48. Rajendra NS, Ireland S, George J, Belch JJ, Lang CC, Struthers AD. Mechanistic insights into the therapeutic use of high-dose allopurinol in angina pectoris. J Am Coll Cardiol. 2011;58(8):820-8.

49. Feig DI, Soletsky B, Johnson RJ. Effect of allopurinol on blood pressure of adolescents with newly diagnosed essential hypertension: a randomized trial. Jama. 2008:300(8):924-32.

50. Jalal DI, Decker E, Perrenoud L, Nowak KL, Bispham N, Mehta T, Smits G, You Z, Seals D, Chonchol M, et al. Vascular function and uric acid-lowering in stage 3 CKD. J Am Soc Nephrol. 2017;28(3):943-52.

51. Golenbiewski J, Keenan RT. Moving the needle: improving the care of the gout patient. Rheumatol Ther. 2019;6(2):179-93.

52. Kang DH, Han L, Ouyang X, Kahn AM, Kanellis J, Li P, Feng L, Nakagawa T, Watanabe S, Hosoyamada M, et al. Uric acid causes vascular smooth muscle cell proliferation by entering cells via a functional urate transporter. Am J Nephrol. 2005:25(5):425-33.

53. Kirca M, Oguz N, Cetin A, Uzuner F, Yesilkaya A. Uric acid stimulates proliferative pathways in vascular smooth muscle cells through the activation of p38 MAPK, p44/42 MAPK and PDGFRbeta. J Recept Signal Transduct Res. 2017:37(2):167-73.

54. Ives A, Nomura J, Martinon F, Roger T, LeRoy D, Miner JN, Simon G, Busso $\mathrm{N}$, So A. Xanthine oxidoreductase regulates macrophage IL 1 beta secretion upon NLRP3 inflammasome activation. Nat Commun. 2015;6:6555. 
55. Shah B, Toprover M, Crittenden DB, Jeurling S, Pike VC, Krasnokutsky S, Xia Y, Fisher MC, Slobodnick A, Tenner CT, et al. Colchicine use and incident coronary artery disease in male patients with gout. Can J Cardiol. 2020. Online ahead of print.

56. Seropian IM, Toldo S, Van Tassell BW, Abbate A. Anti-inflammatory strategies for ventricular remodeling following ST-segment elevation acute myocardial infarction. J Am Coll Cardiol. 2014;63(16):1593-603.

57. FDA adds Boxed Warning for increased risk of death with gout medicine Uloric (febuxostat). https://www.fda.gov/drugs/drug-safety-and-availability/ fda-adds-boxed-warning-increased-risk-death-gout-medicineuloricfebuxostat. Accessed 7 July 2020.

58. White WB, Saag KG, Becker MA, Borer JS, Gorelick PB, Whelton A, Hunt B, Castillo M, Gunawardhana L, Investigators C. Cardiovascular safety of febuxostat or allopurinol in patients with gout. N Engl J Med. 2018;378(13): 1200-10.

\section{Publisher's Note}

Springer Nature remains neutral with regard to jurisdictional claims in published maps and institutional affiliations.

Ready to submit your research? Choose BMC and benefit from:

- fast, convenient online submission

- thorough peer review by experienced researchers in your field

- rapid publication on acceptance

- support for research data, including large and complex data types

- gold Open Access which fosters wider collaboration and increased citations

- maximum visibility for your research: over $100 \mathrm{M}$ website views per year

At $\mathrm{BMC}$, research is always in progress.

Learn more biomedcentral.com/submissions 